\title{
Effect of symbiotic association of rhizobia and endomycorrhizae from Moroccan arid littoral dunes on Acacia cyanophylla tolerance to drought
}

\author{
ABDELHAKIM HATIMI ${ }^{1}$, SAIDIA TAHROUCH ${ }^{1}$, BRAHIM BOUIZGARNE ${ }^{1, \bullet}$ \\ Laboratoire de Biotechnologie végétale, Equipe de Phytochimie-Microbiologie plante-sol, Faculté Des Sciences, Université Ibn Zohr. B.P 8106, Agadir \\ 80000, Morocco. `email: b.bouizgarne@uiz.ac.ma
}

Manuscript received: 8 July 2018. Revision accepted: 7 August 2018.

\begin{abstract}
Hatimi A, Tahrouch S, Bouizgarne B. 2018. Effect of symbiotic association of rhizobia and endomycorrhizae from Moroccan arid littoral dunes on Acacia cyanophylla tolerance to drought. Asian J For 2: 39-45. Coastal sand dunes in arid region serve as habitat of coastal biotas including rhizobia and mycorrhiza. This research aimed to investigate the effect of selected symbiotic rhizobia native from coastal dunes of Souss-Massa, Morocco, alone or in association with endomycorrhiza to improve the tolerance of Acacia cyanophylla plants to drought stress. A symbiotic indigenous endomycorrhizal fungi $\mathrm{M}$, and three rhizobia isolates (i.e., two slowgrowing isolates R1 (Bradyrhizobium sp. RCM6), and R2 (Bradyrhizobium sp. RLC3) and a fast-growing isolates R3 (Rhizobium sp. S21)) were inoculated to A. cyanophylla under drought stress conditions in greenhouse. Results showed that the growth and nutrition of seedlings of A. cyanophylla were drastically affected after two months in drought stress conditions. However, inoculation of the symbiotic microorganisms either alone (treatments M, RMC6, R2 or R3) or as inoculums consisting of combination of the rhizobia with the endomycorrhiza (treatments MR1, MR2 or MR3) resulted in enhanced tolerance of A. cyanophylla seedlings to drought stress. At $100 \%$ of field capacity (fc), all treatments showed a significant improvement of plant growth compared to non-inoculated plants in stress conditions. In addition, Bradyrhizobium RCM6 (R1) holds a high efficiency to improve the growth and nutrition of the host plant. Indeed, higher number of nodules/plant and higher amount of total nitrogen were recorded in the seedlings inoculated with Bradyrhizobium sp. RCM6 in comparison with plants inoculated with the two other rhizobia Bradyrhizobium sp. RLC3 (R2) and Rhizobium sp. S21 (R3), and control plants. Dual inoculation with each of the three rhizobia and the endomycorrhizal complex (M) led to higher water content (WC) and relative water content (RWC) and a significant increase in Phosphorus content of the aerial part. While positive effects were recorded for Phosphorus, no such effects were recorded for nitrogen. However, the overall results showed the importance of the use of microorganisms in the dune coastal environment particularly adequate tripartite association: rhizobia Endomycorrhizes-A. cyanophylla in enhancing tolerance to drought stress.
\end{abstract}

Keywords: Acacia cyanophylla, endomycorrhizae, plant growth and nutrition, Rhizobia, drought stress

\section{INTRODUCTION}

Coastal dunes are characterized by the presence of vegetation, which plays an important role in the fixation of sand to form dunes. These dunes are very beneficial to mitigate beach abrasion, storm avoidance and habitat of coastal biotas including rhizobia and mycorrhiza.

Coastal dunes in Sous-Massa, South-West of Morocco have a very low vegetation cover dominated by two legumes (Retama monosperma and Ononis natrix) and Gramineae species Schismus barbatus (Hatimi and Tahrouch, 2007). In this region, Acacia cyanophylla is used for the fight against desertification, coastal dune fixation, forage production and wood supply.

In the coastal region of Souss-Massa, drought is the main constraint to crop production (Sanchez-Diaz et al. 1995). This arid area is known for low rainfall and high temperatures that lead to increased soil salinity. Simultaneously, such climate and soil factors have adverse effects on plants due to limited water availability and nutrient losses. Water stress conditions can also influence soil microflora, for example, it could disturb the symbiotic microorganisms of rhizobia and endomycorrhiza.

In general, drought stress affects the degree of legumes infection by rhizobia (Mnasri et al. 2007) and $\mathrm{N}_{2}$ fixation in legumes (Marques et al. 2001; Mnasri et al. 2007; Gong et al. 2013). Acacia plants could undergo deleterious drought effects in arid areas. However, the role of Acacia as biological dune fixation is limited by the lack of water. Many studies indicate that it is possible to select rhizobia strains resistant to drought and showing also high nitrogenfixation effectiveness (Shoushtasi and Papper 1985a, 1985b; Romdhane et al. 2008, 2009).

In addition to nitrogen, the beneficial roles of mycorrhizal fungi are proved to be relevant in providing better phosphorus supply to plants (Barea et al. 2005; Wu et al. 2007; Evelin et al. 2012), to induce changes in water relations of plants (Marulanda et al. 2007; Porcel and RuizLozano 2004; Ruiz-Lozano and Aroca 2006; Bárzana et al. 2012), to induce higher water conductivities and more effective water uptake (Fagbola et al. 2001; Augé 2001; Aroca et al. 2007) and to increase in growth rate and biomass (Porcel and Ruiz-Lozano 2004; Wu et al. 2008). Many kinds of research also noted the importance of using tripartite association legume-rhizobia-mycorrhizal symbiosis 
as efficient system in harsh conditions (Marques et al. 2001; Ruiz-Lozano et al. 2001; Porcel and Ruiz-Lozano 2004; Barea et al. 2005; Aroca et al. 2007; Sprent and James 2007; Bouizgarne et al. 2015). In this framework, the aims of this research were to investigate the effect of selected symbiotic rhizobia, alone or in association with endomycorrhiza to improve the tolerance of A. cyanophylla plants to drought stress

\section{MATERIALS AND METHODS}

\section{Plant materials}

The study focused on Acacia cyanophylla, a leguminous tree originating from Australia. The plant has a particularly deep root system, rapid growth and great adaptation to the dune environment. Acacia cyanophylla is useful to fix both the dune sands and the ravines banks, and is one of the basic materials in forest grazing areas due to the feed value of its leaves and pods. For these reasons, Water and Forest Service of the Government of Morocco introduced this species in order to increase the biological stabilization of coastal dunes in Souss-Massa region in the southern part of Agadir Province, South of Morocco.

Four inocula those were A mycorhizogen complex (M), consisting of a consortium of endomycorrhizal fungi obtained from the dune soil from Lamzar region with high colonization potential of Allium porrum roots (Plenchette et al. 1989). Three isolates of rhizobia: two isolates of the slow-growing Bradyrhizobium: Bradyrhizobium sp., RCM6 (R1), RLC3 (R2) and one isolate of fast-growing Rhizobium sp., S21 (R3) isolated from the nodules of Acacia cyanophylla collected from three different areas of the high saline coastal dunes of Souss-Massa.

\section{Methods}

Cultures

Seeds of Acacia cyanophylla were scarified and disinfected through one-hour immersion in concentrated sulfuric acid. Subsequently, they were allowed to germinate for 7 days in sterile vermiculite. Seedlings of the same size were then transplanted into pots (two seedlings per pot). Each pot contained $2 \mathrm{~kg}$ of a $1: 1(\mathrm{w} / \mathrm{w})$ sandvermiculite mixture which was previously washed vigorously and autoclaved twice at $120{ }^{\circ} \mathrm{C}$ for 1 hour. The pots were then transferred to greenhouse, maintained at temperatures of approximately $28^{\circ} \mathrm{C}$ at day and $20^{\circ} \mathrm{C}$ at night and 12 hours photoperiod after 7 days of culture. Treatments consisting of inoculation of seedlings with each of the three rhizobia Bradyrhizobium spRCM6 (R1), Bradyrhizobium sp. RLC3(R2) and Rhizobium sp, S21 (R3) either alone or in combination with the mycorrhiza mixture (M) were performed: plants were inoculated with $1 \mathrm{ml}$ of a rhizobial suspension at $10^{8}$ cells. $\mathrm{ml}^{-1}$ according to Ames and Bergman 1984 or $1 \mathrm{~g}$ of the mycorrhized leek roots according to Plenchette et al. (1989). Dual inoculations consisted of $10^{8}$ cells. $\mathrm{ml}^{-1}$ rhizobial cells and $1 \mathrm{~g}$ of the mycorrhized leek roots. Seven inoculation treatments were applied: R1, R2, R3, M, R1+M, R2+M and R3+M and twelve seedlings were used for each inoculation. Uninoculated plants served as the control.

Drought stress was applied three weeks after inoculation by microorganisms in order to allow time for the establishment of symbiosis. Three water regimes were applied to each treatment: 100, 50 and $25 \%$ of field capacity (FC). Along with the experiments where seedlings are exposed to drought stress, the pots water content was adjusted to the weight corresponding to each drought stress level by successive weighing and adding the water. Seedlings received a weekly basic nutrient solution according to Marcar et al. (1991). Both mycorrhizal (M) treatment and uninoculated seedlings (control) received $200 \mathrm{mg} \mathrm{N} \mathrm{L}^{-1}$ as ammonium nitrate in addition to the nutrient solution (Zou et al. 1995). Four replicates of each of the three drought treatments, each consisting of twelve inoculated and uninoculated seedlings were used.

\section{Plant harvest, growth and mineral nutrition}

After two months of drought stress, we estimated the growth and mineral nutrition in A. cyanophylla seedlings by measuring the growth, water content, degree of root infection and mineral element parameters.

The growth of A. cyanophylla was estimated by measuring the length of the plant aerial system and the biomass produced. The latter was measured by determining the fresh and dry weight of shoot and root parts of the plant. The dry weight was obtained after drying shoots and roots separately after incubation for 48 hours at $80^{\circ} \mathrm{C}$. Comparison of dry matter production in stressed and unstressed seedlings $(\operatorname{Pr} \%)$ that provides information on the degree of stress tolerance of the plant was calculated as:

$$
\begin{aligned}
& \operatorname{Pr}(\%)=100(\text { SSDW/NSSDW }) \\
& \text { Where: } \\
& \text { SSDW = Dry weight of the stressed seedling } \\
& \text { NSSDW = Dry weight of the stressed seedling }
\end{aligned}
$$

Water content (W. C) was determined by the difference between fresh material (FW) and the dry matter (DW) weight and is expressed in grams of water per gram of dry matter. Values represent the mean of four replications and results are presented as mean $\pm \mathrm{SD}$.

$$
\text { W. C }(\text { g H2O/g MS })=(F W-D W) / D W
$$

Relative water content (RWC) was measured in the last fully developed leaf from the top of the stem (leaf whose growth is complete). RWC is calculated from the formula:

$$
\text { RWC }(\%)=100 \times(F W-D W) /(\text { RW-DW })
$$

Where:

FW: Fresh weight of the leaf weighed immediately $80^{\circ} \mathrm{C}$.

DW: dry weight after drying for 48 hours the leaf at

RW: rehydrated Weight by immersion in distilled water for $18 \mathrm{~h}$ at $4{ }^{\circ} \mathrm{C}$ in the dark. 
Values represent the mean of four replications and results are presented as mean $\pm \mathrm{SD}$.

Infection by Rhizobia was evaluated by counting the number of nodules formed on the roots (n) and recording their dry weight (DWn) after drying at $80{ }^{\circ} \mathrm{C}$ for 48 hours.

The degree of mycorrhizal infection was evaluated by the frequency of infection (F\%) according to Trouvelot et al. (1986) below:

$$
\mathrm{F}(\%)=100(\mathrm{~N}-\mathrm{No}) / \mathrm{N}
$$

Where:

$\mathrm{N}$ : number of root fragments observed $(=20)$

No: number of fragments without mycorrhization.

Values represent the mean of four replications and results are presented as mean \pm SD.

Total nitrogen $(\mathrm{N})$ of aerial and root parts of the plant was measured by the Kjeldahl method for organic nitrogen digestion and reduction of nitrates eventually present. Total Phosphorus $(\mathrm{P})$ in plant tissue was measured by the nitrovanado-molybdate method (Jackson, 1958). Potassium content $(\mathrm{K})$ was determined by flame-emission spectrophotometry (type 90D LISABIO PHE) (Rodier
1984). Values represent the mean of four replications and results are presented as mean \pm SD.

\section{RESULTS AND DISCUSSION}

\section{Effect of symbiont on plant growth}

At $100 \%$ of field capacity (FC), considered optimal moisture state, plant growth of A. cyanophylla associated with root symbionts showed a significant improvement compared with non-inoculated plants. The improvement in growth resulted in the increase in the length of the aerial part of the plant (Figure 1) and in the production of fresh matter of the aerial part of the plant (Figure 2). Increases in the production of dry matter in treatment R1, M and MR1 were 2 to 2.5 times higher than in the uninoculated control treatment (Table 1). The application of drought stress of $50 \%$ or $25 \%$ of FC, led to reduced growth in length (Figure 1) and biomass production (Figure 2 and Table 1) in all treatments and we noted that the aerial part of the plant seems to be the most sensitive to drought stress. However, the ratio of dry matter of the stressed plants to that in unstressed plants (100\% of FC) was greater in inoculated plants (Table 1). This reflects the tolerance of inoculum complex-host plant to water deficit. This tolerance was very significant $(\mathrm{P}<0.05)$ with all endomycorrhiza treatments (M, MR1, MR2, and MR3).

Table 1. Variation of dry matter of the aerial part of the plant (SDW), roots dry matter (RDW), total dry matter (TDW), water content (WC) of the aerial part of the plant and foliar relative water content (RWC) in A. cyanophylla inoculated by three isolates of rhizobia RCM6 (R1) RLC3 (R2) and S21 (R3) and /or mycorrhizae complex (M), and exposed to three decreasing water regimes 100\%, 50\% and $25 \%$ of full capacity*.

\begin{tabular}{lccccccc}
\hline Treatment & $\begin{array}{c}\text { Water regime } \\
(\boldsymbol{\%} \text { of } \mathbf{F C})\end{array}$ & SDW $(\mathbf{g})$ & RDW $(\mathbf{g})$ & TDW $(\mathbf{g})$ & Pr** $(\boldsymbol{\%})$ & W. C. (g/g MS) & $\begin{array}{c}\text { R. W. C. } \\
(\boldsymbol{\%})\end{array}$ \\
\hline Control & 100 & $2.88 \pm 0.13$ & $1.05 \pm 0.13$ & $3.93 \pm 0.25$ & 100 & $2.84 \pm 0.09$ & $90 \pm 1.83$ \\
& 50 & $0.85 \pm 0.17$ & $0.58 \pm 0.06$ & $1.43 \pm 0.12$ & 36 & $1.83 \pm 0.05$ & $75 \pm 3.83$ \\
& 25 & $0.56 \pm 0.19$ & $0.39 \pm 0.07$ & $0.95 \pm 0.14$ & 24 & $1.03 \pm 0.06$ & $65 \pm 3.16$ \\
R1 & 100 & $7.52 \pm 0.99$ & $1.38 \pm 0.25$ & $8.90 \pm 0.84$ & 100 & $4.62 \pm 0.27$ & $92 \pm 2.94$ \\
& 50 & $4.59 \pm 0.49$ & $1.06 \pm 0.08$ & $5.65 \pm 0.51$ & 64 & $3.98 \pm 0.14$ & $85 \pm 3.37$ \\
& 25 & $3.00 \pm 0.22$ & $0.59 \pm 0.06$ & $3.59 \pm 0.23$ & 44 & $1.78 \pm 0.17$ & $80 \pm 3.37$ \\
R2 & 100 & $4.98 \pm 0.56$ & $1.38 \pm 0.23$ & $6.36 \pm 0.52$ & 100 & $3.90 \pm 0.48$ & $93 \pm 2.94$ \\
& 50 & $3.00 \pm 0.15$ & $1.26 \pm 0.24$ & $4.26 \pm 0.17$ & 67 & $2.69 \pm 0.36$ & $85 \pm 3.20$ \\
& 25 & $2.32 \pm 0.50$ & $0.80 \pm 0.07$ & $3.12 \pm 0.54$ & 49 & $1.82 \pm 0.19$ & $84 \pm 2.87$ \\
& 100 & $3.23 \pm 0.41$ & $0.54 \pm 0.09$ & $3.77 \pm 0.43$ & 100 & $3.41 \pm 0.37$ & $90 \pm 1.83$ \\
R3 & 50 & $1.55 \pm 0.30$ & $0.36 \pm 0.02$ & $1.91 \pm 0.29$ & 51 & $2.82 \pm 0.19$ & $85 \pm 2.16$ \\
& 25 & $1.15 \pm 0.13$ & $0.29 \pm 0.01$ & $1.43 \pm 0.13$ & 38 & $1.34 \pm 0.17$ & $70 \pm 3.83$ \\
M & 100 & $6.68 \pm 0.46$ & $1.04 \pm 0.09$ & $7.72 \pm 0.44$ & 100 & $4.24 \pm 0.37$ & $94 \pm 3.50$ \\
& 50 & $4.67 \pm 0.14$ & $0.49 \pm 0.05$ & $5.16 \pm 0.14$ & 67 & $3.39 \pm 0.26$ & $88 \pm 1.63$ \\
& 25 & $3.37 \pm 0.08$ & $0.88 \pm 0.10$ & $4.25 \pm 0.17$ & 55 & $2.64 \pm 0.20$ & $87 \pm 0.82$ \\
M+R1 & 100 & $6.65 \pm 0.29$ & $0.88 \pm 0.09$ & $7.53 \pm 0.33$ & 100 & $5.89 \pm 0.44$ & $96 \pm 2.87$ \\
& 50 & $4.58 \pm 0.17$ & $0.82 \pm 0.11$ & $5.40 \pm 0.15$ & 72 & $4.39 \pm 0.18$ & $88 \pm 2.71$ \\
& 25 & $3.47 \pm 0.45$ & $0.27 \pm 0.05$ & $3.74 \pm 0.49$ & 50 & $2.88 \pm 0.33$ & $85 \pm 2.16$ \\
M+R2 & 100 & $5.75 \pm 0.07$ & $0.48 \pm 0.10$ & $6.22 \pm 0.06$ & 100 & $4.28 \pm 0.32$ & $94 \pm 2.63$ \\
& 50 & $3.96 \pm 0.11$ & $0.68 \pm 0.13$ & $4.64 \pm 0.16$ & 75 & $3.97 \pm 0.10$ & $90 \pm 2.16$ \\
& 25 & $2.81 \pm 0.11$ & $0.40 \pm 0.07$ & $3.21 \pm 0.10$ & 52 & $2.75 \pm 0.11$ & $88 \pm 1.41$ \\
M+R3 & 100 & $3.65 \pm 0.19$ & $1.16 \pm 0.10$ & $4.81 \pm 0.27$ & 100 & $3.33 \pm 0.30$ & $93 \pm 2.87$ \\
& 50 & $2.01 \pm 0.14$ & $0.48 \pm 0.11$ & $2.49 \pm 0.24$ & 52 & $3.04 \pm 0.09$ & $84 \pm 2.50$ \\
LSD, $P=05$ & 25 & $1.47 \pm 0.17$ & $0.76 \pm 0.15$ & $2.23 \pm 0.24$ & 50 & $2.57 \pm 0.15$ & $80 \pm 1.83$ \\
\hline & & 0,50 & 0.18 & 0.48 & & 0.36 \\
\hline
\end{tabular}

Note: * FC*: field capacity;** Pr: percentage of total dry matter production by stressed plants in comparison with non stressed plants. 


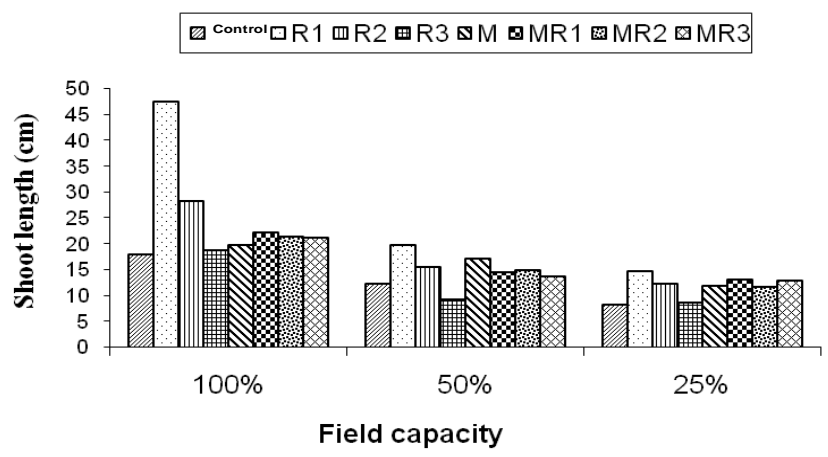

Figure 1. Growth of aerial part of inoculated A. cyanophylla plants and subjected to drought stress at 25 and $50 \%$ field capacity. M: Mycorrhizal complex, R1: Bradyrhizobium sp. RCM6, R2: Bradyrhizobium sp., RLC3 and R3: Rhizobium sp., $\mathrm{S} 21$.

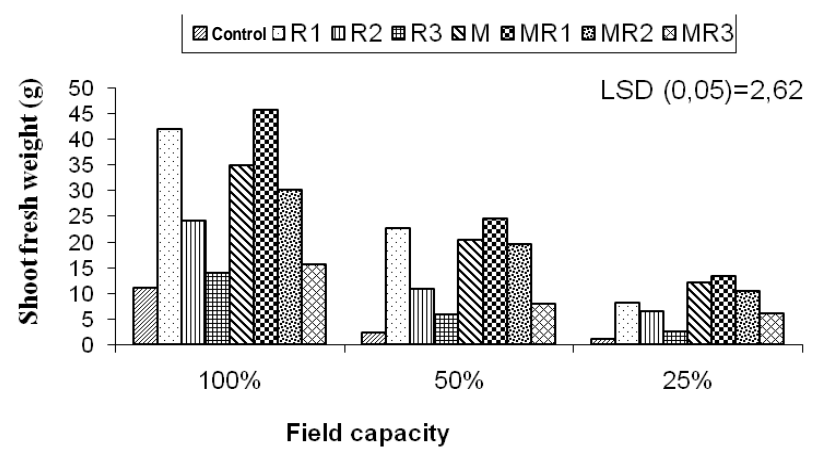

Figure 2. Production of fresh matter in aerial part of inoculated $A$. cyanophylla seedlings and subjected to drought stress. $\mathrm{M}$ : Mycorrhizal complex, R1: Bradyrhizobium sp., RCM6, R2: Bradyrhizobium sp., RLC3, and R3: Rhizobium sp., S21.

\section{Water contents}

At $100 \%$ of field capacity, there has been an increase in the water content (WC) of the aerial part of inoculated plants, ranging from 20 to $100 \%$ compared to noninoculated plants (Table 1). However, in the same water conditions, a slight nonsignificant increase in foliar relative water content (RWC) was observed in plants in symbiotic association. WC of the aerial part of the plant and foliar RWC decreased depending on the degree of applied water deficit. However, the amount of water was always higher in inoculated plants, especially in mycorrhized plants. For instance, at $25 \%$ of field capacity, increase in foliar RWC ranged from 7 to $20 \%$ in plants inoculated with rhizobia and from 23 to $33 \%$ in mycorrhized plants when compared to uninoculated control.

\section{Effect on symbioses: nodular and mycorrhizal infection}

The number of nodules per plant was very important in R1 treatment, at $100 \%$ of full capacity with 60.5 nodules per plant compared to 46.25 and 32 nodules per plant respectively, in R2 and R3 treatments (Figure 3A). In the same water conditions, the number of formed nodules decreased in the presence of endomycorrhizal fungal mixture (M). Indeed, a reduction of more than 30\% in MR1 treatment was observed. Generally, nodules dry weight per plant decreased in the same way as the number of nodules (Figure 3B). Drought stress application of $50 \%$ or $25 \%$ of field capacity had a very negative effect on the amount of formed nodules and their dry weight regardless of the treatment used. However, the effect of water deficit on the formation of nodules was strongly reduced with treatment R2. Results also showed that the mycorrhization reduced but in a non-significant way $(\mathrm{P}>0.05)$ the effect of stress on the formation of nodules. Figure $3 \mathrm{C}$ shows that the difference in mycorrhizal infection degree among treatments and between the different drought stress levels was not significant.

\section{Effect of mineral nutrition}

The highest amount of total nitrogen was recorded in the seedlings inoculated with the rhizobia (Fig. 4A). The high concentration of nitrogen was obtained with treatment $\mathrm{R} 1$, with $82.87 \mathrm{mg}$ per plant against only $14.55 \mathrm{mg}$ only in the uninoculated plants. At optimal moisture (100\% of field capacity), the amount of accumulated total phosphorus was very high among plants inoculated with endomycorrhizal fungi (Figure 4B). These amounts were 4 to 6 times higher than those recorded for the non-inoculated control treatment. A significant increase in the amount of phosphorus was observed in treatments $\mathrm{R} 1$ and R2, respectively with 29.94 and $17.31 \mathrm{mg}$ per plant whereas only $11.6 \mathrm{mg}$ per plant was recorded in the non-inoculated treatment. However, in the R3 treatment, the amount of phosphorus was identical to that of non-inoculated plants. The highest concentrations were also observed in mycorrhizal plants. For potassium, large amounts were measured in inoculated plants and especially among mycorrhized plants (Figure 4C). When applying drought stress, the accumulation of total nitrogen in plant tissue decreased dramatically. The potassium content had a similar trend as nitrogen. However, with mycorrhiza, a decrease in the amount of nitrogen was noted and potassium content has reduced while the content of phosphorus varied little with drought stress $(\mathrm{P}<0.05)$.

\section{Discussion}

Rhizobia are capable of withstanding water potentials lower than a great number of higher plant cells (SanchezDiaz et al. 1995). Results obtained in this investigation showed that growth is the first mechanism affected by water deficiency. According to Blanchet et al. (1977), the production of the total dry matter is proportional to the amount of consumed water. At all levels of stress, growth and nutrition are generally greater in inoculated $A$. cyanophylla seedlings when compared with non-inoculated seedlings. The response of root symbionts to drought stress differs from one treatment to another. Indeed, better growth was observed with the strain R1 and a larger tolerance with the strain R2 while strain R3 had no effect on growth and tolerance to drought stress of A. cyanophylla. Furthermore, the double inoculation $\mathrm{M}+\mathrm{R}$ has variable effects 
according to rhizobia strains. In fact, with this treatment, a reduction in the efficiency of the $\mathrm{R} 1$ strain on the growth of A. cyanophylla was observed. Similar results were obtained by Lal and Khanna (1993) who worked on the GlomusRhizobium-A. nilotica association. However, we reached an increased tolerance of the three strains of rhizobia to drought stress when they are associated with the endomycorrhizal complex. In treatments that have shown tolerance to drought stress, we noticed greater water content (WC) and relative water content (RWC) than in non-inoculated control plants. Similar results were obtained in mycorrhized plants subjected to drought stress in Trifolium (clover) (Meddich 1997; Meddich et al. 2000), Lactuca sativa (Ruiz-Lozano and Azcon 1997) and Fragaria ananassa (Hernandez-Sebastia et al. 1999). At $25 \%$ of field capacity, RWC was $7-20 \%$ and $23-33 \%$ higher, respectively, in rhizobia inoculated A. cyanophylla seedlings and double inoculated seedlings $(\mathrm{R}+\mathrm{M})$. This result highlighted one of the beneficial endomycorrhizal fungi roles which is the great ability to provide water, especially in the case of drought conditions (Aroca et al. 2007, Bárzana et al. 2012).
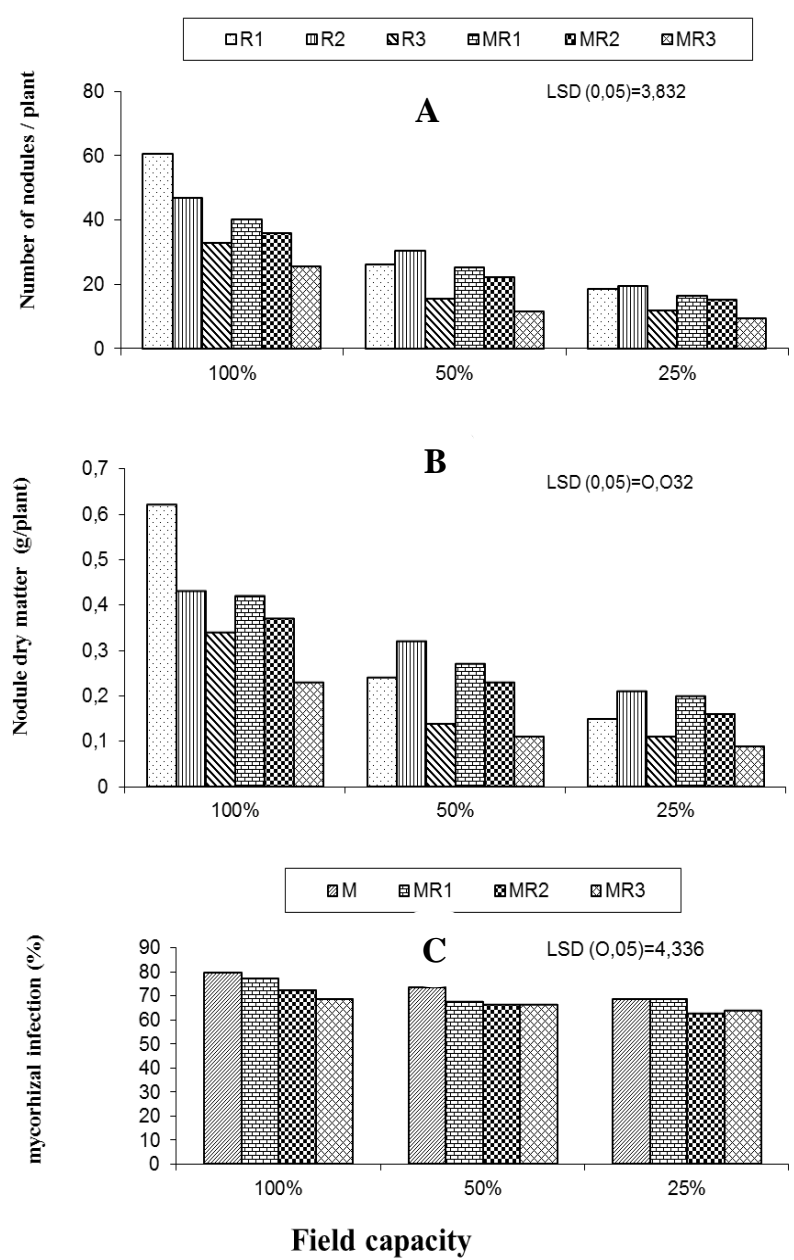

Figure 3. Number of nodules (A), nodules dry matter weight (B) mycorrhizal infection degree (C) of inoculated A. cyanophylla seedlings and subjected to drought stress. M: Mycorrhizal complex, R1: Bradyrhizobium sp., RCM6, R2: Bradyrhizobium sp., RLC3, and R3: Rhizobium sp., S21.
The water deficiency also affected the degree of legumes infection by rhizobia (Figure 3). In our investigation, the number and dry weight of nodules were affected by drought stress. The reduction was recorded for all treatments. This was observed in many kinds of research. Indeed, establishment of nodulation in the legume-rhizobium symbiosis has long been recognized as being sensitive to drought stress since it is usually associated with a drastic decline in the number of nodules (Soria et al. 1996; Ramos et al. 1999; Sinclair et al. 2001; Mnasri et al. 2007). Therefore, deleterious physiological effects of water deficiency include reduction in nitrogen fixation (Sharma et al. 2010), nodular activity (Sprent 1976; Aparicio-Tejo et al. 1980; Sprent 1981; Serraj et al. 1999) and photosynthesis (Huang et al. 1975), permeability of nodules to oxygen (Aguirreolea and Sanchez-Diaz 1989) and oxidative phosphorylation (Sheehy et al. 1985) have been demonstrated. Unlike infectivity by rhizobia, mycorrhization of A. cyanophylla roots was not affected by drought stress. Similar results were obtained by SanchezDiaz et al. (1990). The presence of endomycorrhizal fungi
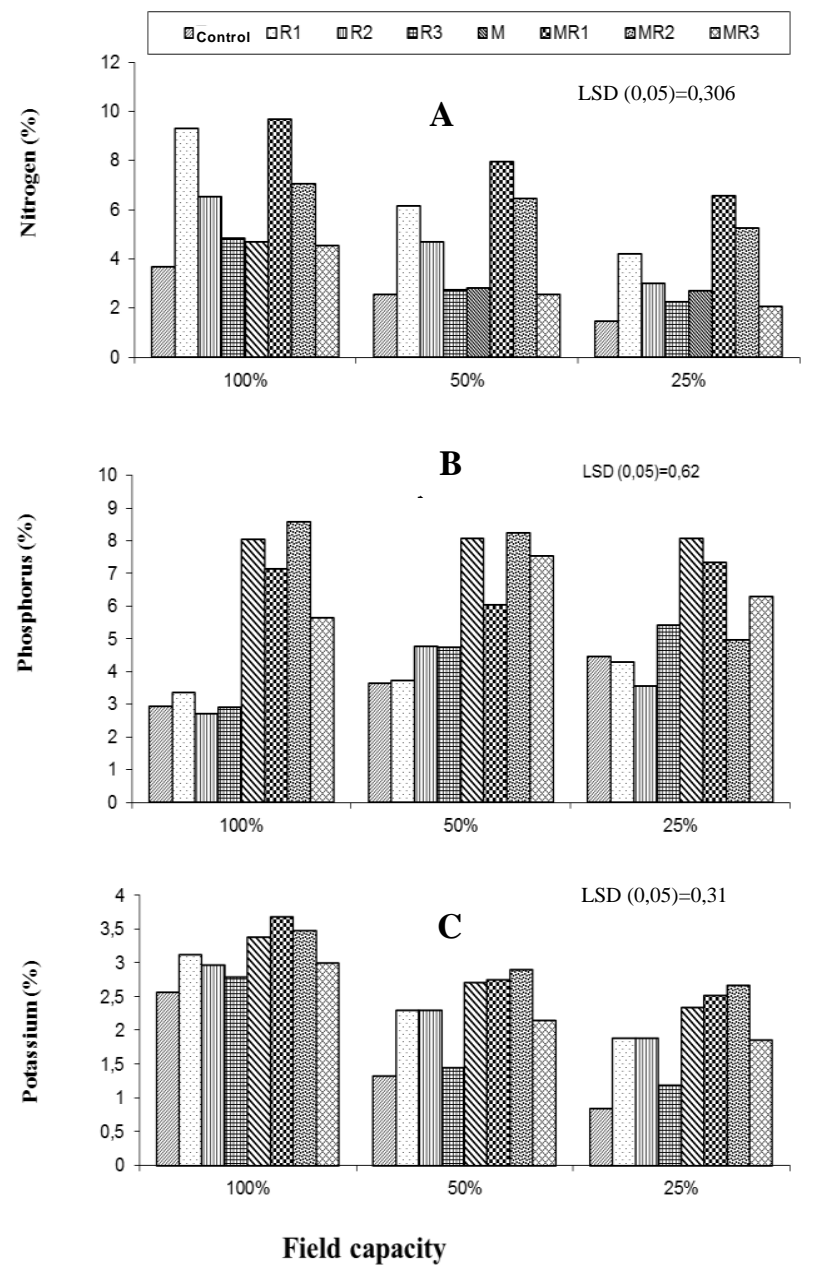

Figure 4. Nitrogen (A), phosphorus (B) and potassium (C) concentration in shoot of inoculated A. cyanophylla seedlings and subjected to drought stress. M: Mycorrhizal complex, R1: Bradyrhizobium sp., RCM6, R2: Bradyrhizobium sp., RLC3, and R3: Rhizobium sp., S21. 
significantly increased the $\mathrm{P}$ content of the aerial part of $A$. cyanophylla (Figure 4A). In general, positive effects of endomycorrhizal fungi on phosphorus uptake have been demonstrated by several authors (Hatimi 1995; Oihabi and Meddich 1996; Barea et al. 2005; Wu et al. 2007; Evelin et al. 2012).

Studies on phosphate nutrition drought-stress relationship in Acacia plants are scarce. In our study on A. cyanophylla, we obtained an accumulation of $\mathrm{P}$ in stressed plants. Indeed, treatments showing some stress tolerance, generally in association with endomycorrhizal fungi, have a higher content of $\mathrm{P}$ at the severe drought condition of $25 \%$ of field capacity. This high content can be attributed to the degree of infection that was not influenced by the water deficit whereas nitrogen nutrition has not overcome the effects of drought stress. The accumulation of total nitrogen decreased in the tissue of stressed plants even in inoculated plants. Regarding N nutrition, it is well known that the water deficit can act negatively either on the infective capacity of microsymbionts (Mnasri et al. 2007) and the activity of nitrogenase in nodules (Porcel et al. 2003; Naya et al. 2007). In contrast, the effect of stress on the absorption of potassium is relatively reduced when plants are mycorrhized. Indeed, potassium plays a key role in the maintenance of turgor of plant cells (Evelin et al. 2012).

Authors agreed that endomycorrhizal fungi have positive effects on plant photosynthesis and growth (Pena et al. 1988; Sanchez-Diaz et al. 1990; Gong et al. 2013). Sanchez-Diaz et al. (1995) also observed that the extent of mycorrhizal fungi infection was not affected by drought. On the contrary, Meddich et al. (2000) reported that the more drought stress increases, the more the rate of infection of clover (Trifolium) by indigenous strains of arbuscular mycorrhiza decreased whereas Goicoechea et al. (1994), observed that alfalfa mycorrhized plants are not affected by drought in their content of cytokinins in comparison with non-mycorrhized plants, suggesting an increase of growth capacity in mycorrhized plants. Although there is growing evidence on the possibility of increased tolerance to drought of mycorrhized legumes due to a better water supply and phosphorus (Berea and Azcòn-Aguilar 1983), it is difficult to distinguish between direct effects of the mycorrhizae and those that could occur through improved nitrogen nutrition by rhizobia.

Results after two months of stress have clearly shown that the growth and nutrition of A. cyanophylla seedlings are affected by water deficiency. However, the study has highlighted the importance of inoculation in the tolerance of A. cyanophylla plants to stress. Thus, it was shown in this study that the strain of Bradyrhizobium RCM6 (R1) native to dune Massa is endowed with great effectiveness in improving the growth and nutrition of the host plant.

The study also demonstrated the positive role of the tripartite association performed by double inoculation with rhizobia and endomycorrhizal complex from Lamzar dunes. The stress tolerance of the double inoculation is probably related to the roles of endomycorrhizal fungi in increasing the relative water content and the levels of phosphorus and potassium in stressed A. cyanophylla. The water deficit is a limiting factor of the vegetation in arid and semi-arid areas and particularly of coastal dunes. However, in these zones, this factor is related to soil salinity. Indeed, the two phenomena are physiologically dependent. The impact of salinity on the behavior of seedlings $A$. cyanophylla in symbiosis was demonstrated in our previous works.

\section{REFERENCES}

Aguirreolea J, Sanchez-Diaz M. 1989. $\mathrm{CO}_{2}$ evolution by nodulated roots in Medicago sativa L. under water stress. J Plant Physiol 134: 598602. DOI: 10.1016/S0176-1617(89)80154-3

Aparicio-Tejo PM, Sanchez-Diaz J, Pena I. 1980. Nitrogen fixation, stomatal response and transpiration in Medicago sativa, Trifolium repens and T. subterraneum under water stress and recovery. Physiol Plant 48: 1-4. DOI: 10.1111/j.1399-3054.1980.tb03209.x

Aroca R, Porcel R, Ruiz-Lozano JM. 2007. How does arbuscular mycorrhizal symbiosis regulate root hydraulic properties and plasma membrane aquaporins in Phaseolus vulgaris under drought, cold or salinity stresses? New Phytol 173: 808-816. DOI: 10.1111/j.14698137.2006.01961.x

Augé RM. 2001. Water relations, drought, and VA mycorrhizal symbiosis. Mycorrhiza 11: 3-42. DOI: 10.1007/s005720100097

Barea JM, Werner D, Azcón-Guilar C, Azcón R. 2005. Interactions of arbuscular mycorrhiza and nitrogen-fixing symbiosis in sustainable agriculture. In: Werner D, Newton WE (ed) Nitrogen fixation in agriculture, forestry, ecology and the environment. Springer, Dordrecht.

Bárzana G, Aroca R, Paz JA, Chaumont F, Martinez-Ballest MJ, Carvajal M, Ruiz-Lozano JM. 2012. Arbuscular mycorrhizal symbiosis increases relative apoplastic water flow in roots of the host plant under both well-watered and drought stress conditions. Ann Bot 109: 1009-1017. DOI: $10.1093 / \mathrm{aob} / \mathrm{mcs} 007$

Blanchet R, Gelfi N, Bosc M. 1977. Relation entre consommation d'eau et production de divers types variétaux de Soja (Glycine max. L. Merr.). Ann Agro 28: 261-275.

Bouizgarne B, Oufdou K, Ouhdouch Y. 2015. Actinorhizal and RhizobialLegume symbioses for Alleviation of abiotic stresses. In: Arora NK (ed), Plant Microbes Symbiosis: Applied Facets, Springer, India.

Evelin H, Giri B, Kapoor R. 2012. Contribution of Glomus intraradices inoculation to nutrient acquisition and mitigation of ionic imbalance in NaCl-stressed Trigonella foenum-graecum. Mycorrhiza 22: 203217. DOI: $10.1007 / \mathrm{s} 00572-011-0392-0$

Fagbola O, Osonubi K, Mulongoy SA, Odunfa S. 2001. Effects of drought stress and arbuscular mycorrhiza on growth of Gliricidia Sepium (Jacg.), Walp. and Leucaena leucocephala (Lam) de wit. In simulated eroded soil conditions. Mycorrhiza 11: 215-223. DOI: $10.1007 / \mathrm{s} 005720100114$

Gong M, Tang M, Chen H, Zhang Q, Feng X. 2013. Effects of two Glomus species on the growth and physiological performance of Sophora davidii seedlings under water stress. New Forests 44: 399408. DOI: $10.1007 / \mathrm{s} 11056-012-9349-1$

Hernandez-Sebastia C, Piche Y, Desjardins Y. 1999. Water relations of whole strawberry plantlets in vitro inoculated with Glomus intraradices in a tripartite culture system. Plant Sci 143: 81-91. DOI: 10.1016/S0168-9452(99)00014-X

Hatimi A. 1995. Symbiotes racinaires de trois legumineuses arborescentes de dunes littorales de Souss-Massa. Ed. INRA, Paris, Les Colloques 77: $183-190$.

Hatimi A, Tahrouch S. 2007. Caractérisations chimique, botanique et microbiologique du sol des dunes littorales du Souss-Massa. Biomatec Echo 2: 85-97.

Hatimi A. 1999. Effect of salinity on the association between root symbionts and Acacia cyanophylla Lind.: growth and nutrition. Plant Soil 216: 93-101. DOI: 10.1023/A:1004745707277

Huang CY, Boyer JS, Vanderhoef LN. 1975. Limitation of acetylene reduction (nitrogen fixation) by photosynthesis in soybean having low water potentials. Plant Physiol 56: 228-232. DOI: 10.1104/pp.56.2.228 
Lal B, Khanna S. 1993. Renodulation and nitrogen-fixing potential of Acacia nilotica inoculated with Rhizobium isolates. Can J Microbiol 39: 87-91. DOI: 10.1139/m93-012

Marcar NE, Dart P, Sweeney C. 1991. Effect of root-zone salinity on growth and chemical composition of Acacia ampliceps B. R. Maslin, A. auriculiformis A. Cunn. ex Benth. and A. mangium Willd. at two nitrogen levels. New Phytol 119: 567-573.

Marques MS, Pagano M, Scotti MRMML. 2001. Dual inoculation of a woody legume (Centrolobium tomentosum) with rhizobia and mycorrhizal fungi in south-eastern Brazil. Agrofor Syst 52 107-117. DOI: $10.1023 / \mathrm{A}: 1010637401475$

Marulanda A, Porcel R, Barea J. M, Azcón R. 2007. Drought tolerance and antioxidant activities in lavender plants colonized by native drought tolerant or drought sensitive Glomus species. Microb Ecol 54 543-552. DOI: 10.1007/s00248-007-9237-y

Meddich A. 1997. Ecophysiologie des mycorhizes à vésicules et arbusculs des zones arides: effet sur la croissance, la nutrition minérale et la tolérance du trefle (Trifolium alexandrinum) au stress hydrique. Thèse de $3^{\text {ème }}$ cycle.

Meddich A, Oihabi A, , Abbas Y, Bizid E. 2000. Mycorhizes à arbuscules des zones arides: biodiversité et rôles dans la tolérance du trèfle (Trifolium alexandrinum) au stress salin. Agronomie 20: 1-13.

Mnasri B, Aouani ME, Mhamdi R. 2007. Nodulation and growth of common bean (Phaseolus vulgaris) under water deficiency. Soil Biol Biochem 39: 1744-1750. DOI: 10.1016/j.soilbio.2007.01.030

Naya L, Ladrera R, Ramos J, Gonzalez EM, Arrese-Igor C, Minchin FR, Bacana M. 2007. The response of carbon metabolism and antioxidan defenses of alfalfa to drought stress and ro the subsequent recovery of plants. Plant Physiol 113: 259-267. DOI: 10.1104/pp.107.099648

Oihabi A, Meddich A. 1996. Effet des mycorhizes à arbuscules sur la croissance et la composition minérale du trèfle. Cahiers Agricultures 5: 382-388.

Pena JI, Sanchez-Diaz M, Aguirreolea J, Becana M. 1988. Increased stress tolerance of nodule activity in the Medicago-Rhizobium-Glomus symbiosis under drought. J Plant Physiol 133: 79-83. DOI 10.1016/S0176-1617(88)80088-9

Plenchette C, Perrin R, Duvert P. 1989. The concept of soil infectivity and method for its determination as applied to endomycorrhizas. Can J Bot 67: 112-115. DOI: 10.1139/b89-016

Porcel R, Ruiz-Lozano JM. 2004. Arbuscular mycorrhizal influence on leaf water potential, solute accumulation, and oxidative stress in soybean plants subjected to drought stress. J Exp Bot 55: 1743-1750. DOI: $10.1093 / \mathrm{jxb} / \mathrm{erh} 188$

Ramos MLG, Gordon AJ, Minchin FR, Sprent JI, Parsons R. 1999. Effect of water stress on nodule physiology and biochemistry of a drough tolerant cultivar of common bean (Phaseolus vulgaris L.). Ann Bot 83: 57-63. DOI: 10.1006/anbo.1998.0792

Rodier KR. 1984. L'anlyse de l'eau, eaux naturelles, eaux résiduaires, eau de mer. 7ème édition, Dunod.

Romdhane SB, Aouani ME, Trabelsi M, de Lajudie P, Mhamdi R. 2008 Selection of high nitrogen-fixing rhizobia nodulating chickpea (Cicer arietinum) for semi-arid Tunisia. J Agron Crop Sci. 194: 413-420. DOI: 10.1111/j.1439-037X.2008.00328.x

Romdhane SB, Trabelsi M, Aouani ME, de Lajudie P, Mhamdi R. 2009. The diversity of rhizobia nodulating chickpea (Cicer arietinum) under water deficiency as a source of more efficient inoculants. Soil Biol Biochem 41: 2568-2572. DOI: 10.1016/j.soilbio.2009.09.020

Ruiz-Lozano JM, Azcon R. 1997. Hyphal contribution to water uptake in mycorrhizal plants as affected by the fungal species and water status. Physiol Plant 95: 472-478
Ruiz-Lozano JM, Collados C, Barea JM, Azcón R. 2001. Arbuscular mycorrhizal symbiosis can alleviate drought-induced nodule senescence in soybean plants. New Phytol 151: 493-502. DOI: 10.1046/j.0028-646x.2001.00196.x

Ruiz-Lozano JM, Porcel R, Aroca R. 2006. Does the enhanced tolerance of arbuscular mycorrhizal plants to water deficit involve modulation of drought-induced plant genes? New Phytol 171: 693-698. DOI: $10.1111 / \mathrm{j} .1469-8137.2006 .01841 . \mathrm{x}$

Sanchez-Diaz M, Aguirreolea J, Goicochea MC, Antolin MC. 1995. Limitations de la fixation symbiotique d'azote et autres aspects physiologiques des légumineuses des zones méditerranéennes. Ed. INRA, Paris, Les Colloques 77: 11-29.

Sanchez-Diaz M, Pardo M, Antolin M, Pena J, Aguirreolea J. 1990. Effect of water stress on photosynthetic activity in Medicago-RhizobiumGlomus symbiosis. Plant Sci 71: 215-221. DOI: 10.1016/01689452(90)90011-C

Serraj, R, Sinclair TR, Purcell LC. 1999. Symbiotic $\mathrm{N}_{2}$ fixation response to drought. J Exp Bot 50: 143-155.

Sheehy JE, Minchin FR, Witty JF. 1985. Control of nitrogen-fixation in a legume nodule: An analysis of the role of oxygen diffusion in relation to nodule structure. Ann Bot 55: 549-562. DOI: 10.1093/oxfordjournals.aob.a086930

Shoushtasi NH, Pepper IL. 1985a. Mesquite rhizobia isolated from the Sonoran desert: Physiology and effectiveness. Soil Biol Biochem 17: 797-802. DOI: 10.1016/0038-0717(85)90135-X

Shoushtasi NH, Pepper L. 1985b. Mesquite rhizobia isolated from the Sonoran desert: Competitiveness and survival in soil. Soil Biol. Biochem 17: 803-806. DOI: 10.1016/0038-0717(85)90136-1

Sinclair TR, Purcell LC, Vadez V, Serraj R. 2001. Selection of soybean (Glycine $\max$ ) lines for increased tolerance of $\mathrm{N} 2$ fixation to drying soil. Agronomie 21: 653-657.

Soria RD, Correa NS, Rosas SB. 1996. Effect of water stress on the GuarBradyrhizobium system using PEG 6000. Phyton-Intl J Exp Bot 58: 97-106.

Sprent JI, EK. James. 2007. Legume evolution: where do nodules and mycorrhizas fit in? Plant Physiol 144: 575-581. DOI: 10.1104/pp.107.096156

Sprent JI. 1976. Water deficits and nitrogen-fixing root nodules. In: Kozlowski TT (ed). Water deficits and plant growth. Academic Press, New York.

Sprent JI. 1981. Nitrogen fixation. In: Paleg LG, Aspinall D (eds): The Physiology and Biochemistry of drought resistance in plants. Academic Press, Sydney.

Trouvelot A, Kouch J, Gianinazzi-Pearson V. 1986. Mesure du taux de mycorhization VA d'un système radiculaire: Recherche de méthode d'estimation ayant une signification fonctionnelle. Les mycorhizes: Physiologie et Génétique. $1^{\text {er }}$ Séminaire, Dijon, Ed. INRA, Paris.

Wu QS, Xia RX, Zou YN. 2008. Improved soil structure and citrus growth after inoculation with three arbuscular mycorrhizal fungi under drought stress. Eur J Soil Biol 44: 122-128. DOI: 10.1016/j.ejsobi.2007.10.001

Wu QS, Zou YN,. Xia RX, Wang MY. 2007. Five Glomus species affect water relations of Citrus tangerine during drought stress. Bot Stud 48: 147-154.

Zou N, Dart PJ, Marcar N. E. 1995. Interaction of salinity and Rhizobial strain on growth and N2-fixation by Acacia ampliceps. Soil Biol Biochem 27: 409-413. DOI: 10.1016/0038-0717(95)98611-Q 